\title{
A Comparative Study on Clinical Gait Abilities of Stroke Patients According to Indoor and Outdoor Environments
}

\author{
Hyesun Hwanga ${ }^{a}$, Youngkeun Woo ${ }^{b}{ }^{\circledR}$, Yijung Chung ${ }^{c}$ \\ aDepartment of Physical Therapy, Gangdong Wooridle Convalescent Hospital, Seoul, Republic of Korea \\ ${ }^{b}$ Department of Physical Therapy, College of Medical Sciences, Jeonju University, Jeonju, Republic of Korea \\ ${ }^{c}$ Department of Physical Therapy, College of Health and Welfare, Sahmyook University, Seoul, Republic of Korea
}

Objective: This study aimed to compare gait ability through gait evaluations in indoor and outdoor environments according to the general characteristics and walking ability of stroke patients.

Design: Crossed-sectional study.

Methods: The subjects of this study were 57 hospitalized stroke patients. The study subjects were asked to select an indoor environment and an outdoor environment in random order, and the Timed Up and Go Test (TUG), 10-Meter Walk Test (10MWT), Figure-Eight Walk Test (F8WT) and the Functional Gait Assessment (FGA) were used to assess each environment.

Results: The TUG, 10MWT, F8WT time and number of steps, and FGA showed a significant decrease in gait ability in the outdoor environment compared to the indoor environment $(\mathrm{p}<0.05)$. Although the TUG, 10MWT, and the time required for the F8WT were statistically higher in the outdoor compared to the indoor environment at points 2, 3, and 4, but not 5 of the functional ambulatory category (FAC), significant increases in the number of steps of the F8WT were found in the outdoor compared to the indoor environment for only points 2 and 3 of the FAC $(p<0.05)$. In the FAC 3 and 4 , there was a statistically significant decrease in the outdoor compared to the indoor environment only in the FGA $(\mathrm{p}<0.05)$.

Conclusions: Therefore, it has been shown that the gait ability of stroke patients is reduced in the outdoor environment compared to the gait ability in the indoor environment.

Key Words: Environment, Evaluation, Gait, Stroke, Walking speed

\begin{abstract}
서론
뇌졸중 환자 재활 영역에서 기능적 독립성의 확보는 삶 의 질을 개선시키는 중요한 요소로서[1], 특히, 보행 능력 은 뇌졸중 환자의 사회 활동 복귀와 기능적 독립성을 위 해 매우 중요하며, 이러한 능력의 감소는 퇴원 후 뇌졸중 환자의 직장, 레저와 사회 활동 등의 수행 능력의 많은 제 한을 경험하게 한다[2]. 또한, 사회생활과 건강을 위한 일 상 생활에서의 기능적 보행을 위해서는 다양한 도로면과 같은 실외 환경의 걷기 능력이 매우 중요한 요소이다[3]. 이렇듯 뇌졸중 환자에서 퇴원 후 실외 환경에서의 보행 능력의 회복은 필수적인 요소이지만, 실제 실외 환경에서 보행 훈련하는데 많은 제한점이 가지고 있다.
\end{abstract}

de Rooij 등[4]은 대부분의 뇌졸중 환자의 가상 환경 훈련은 기능적 보행 능력 개선 결과에 초점을 두고 있지 만, 실제 뇌졸중 환자 재활에 필요한 일상 생활과 사회 참 여에 초점을 둔 가상 환경 훈련이 필요하며, 이러한 능력 은 지역 사회에 거주할 뇌졸중 환자에게 필요하다고 하였 다. 따라서, 뇌졸중 환자에서 퇴원 후 지역 사회 참여와 사회 복귀를 위한 보행 능력의 회복은 실외 환경에서 실 제 보행 능력을 수행할 수 있는 훈련으로 구성하고, 이를 위해서 실제 실외 보행에서의 능력을 평가하는 것은 필수 적인 요소로 필요하다. 하지만, 실제 실외 환경에서 보행 능력을 평가하는 것은 쉽지 않으며, 대부분의 보행 평가 는 일상 생활 동안의 걷는 행위를 반영하는 것 보다 몇 개의 걸음 주기(gait cycle)의 자료만을 수집하고 있다[5].

Received: Sep 9, 2021 Revised: Sep 17, 2021 Accepted: Sep 21, 2021

Corresponding author: Yijung Chung(ORCID http://orcid.org/0000-0002-2431-8895)

Yijung Chung, 815 Hwarang-ro, Nowon-gu, Seoul [01795]

Tel: +82-2-3399-1637, Fax: +82-2-3399-1639, E-mail: yijung36@syu.ac.kr

This is an Open-Access article distributed under the terms of the Creative Commons Attribution Non-Commercial License (http://creativecommons.org/licenses/ by-nc/4.0) which permits unrestricted non-commercial use, distribution, and reproduction in any medium, provided the original work is properly cited.

Copyright $(2021$ Korean Academy of Physical Therapy Rehabilitation Science 
Ho 등[6]은 보행을 실외 환경에서 측정하는 것은 힘들며, 특히 이동식 측정 도구들이 부족하기 때문에 자연스러운 보행 측정이 어렵다고 하였다. Paraschiv-Ionescu 등[7] 은 현실적인 삶의 조건에서의 보행 변수를 측정하는 것은 어려운 일이며, 표면, 경사, 계단, 실내 환경, 실외 환경 등의 다양성으로 인하여 객관적 측정이 어려우며, 특히 움직임 장애를 가진 신경계 환자의 경우 더욱 어렵다고 하였다. 또한, Storm 등[8]은 실외 환경에서 신체 활동의 움직임을 자연스럽게 측정하고 피험자의 다른 외생 변수 가 발생하지 않게 하려면, 측정 장치의 착용의 최소화나 자연스러운 환경에서 측정이 필요하다고 하였다.

따라서, 본 연구는 동일한 뇌졸중 집단을 대상으로 임 상에서 많이 사용하고 신뢰도와 타당도가 입증된 보행 평 가 도구를 사용하여, 실내 환경과 실외 환경에서의 차이 를 비교하고자 한다. 향후 본 연구는 뇌졸중 환자의 실외 보행 평가를 통해 실외환경에서의 보행 훈련의 필요성을 제시하고, 실외 훈련 프로그램들을 개발할 수 있는 기초 자료로 제시하고자 하였다.

\section{Methods}

\section{Study subjects}

본 연구는 서울시내 재활요양병원에 입원하고 있는 뇌 졸중 환자를 대상으로 선정기준에 부합하는 65 명의 대상 자를 선정하여 측정하였다. 연구 대상자의 선정 조건은 1) 뇌졸중으로 의학적 진단을 받은 자, 2) 한국형 간이 정신 상태 검사(Mini Mental State Examination-Korean, $\mathrm{MMSE}-\mathrm{K}$ ) 점수가 24점 이상, 3) 기능적 이동성 범주 (Functional Ambulation Category, FAC) 2점(1명의 도 움이 지속적 또는 간헐적으로 필요로 하여 체중과 균형의 도움을 받아 10 미터의 거리를 편안한 속도로 보행 할 수 있는 정도) 이상으로 하였다. 제외 조건으로는 1) 뇌졸중 이외의 다른 신경학적 질환이나 골절, 절단이 있거나 관 절 성형 수술을 받은 자, 2) 보행에 영향을 주는 근골격계 손상이 있는 자는 연구 대상자에서 제외하였다.

\section{Study Procedures}

본 측정을 진행하기에 앞서 연구 대상자에게 측정 과정 과 조건에 대하여 충분히 설명하였으며, 동의서에 서명을 받은 자만 측정을 진행하였다. 연구 대상자의 수는 G*Power (version 3.1.9.7., Heinrich-Heine-Universität Düsseldorf, Germany)를 이용하여, 효과 크기 $0.5, \alpha$ 에러 0.05 , 파워 0.95 를 입력하여 계산하였으며, 총 표본 크기는 54명으로 산출하였다. 그리고 탈락률 $20 \%$ 를 고려하여 65 명을 연구 대상자 수를 산출하였다. 또한 본 연구는 삼육대학교 생명
연구윤리위원회의 승인(2-1040781-A-N-012021007HR)을 받은 후 진행하였다.

연구 대상자는 측정 전 전반적인 이동 능력을 알아보기 위하여 기능적 이동성 범주를 사용하여 평가하였다. 연구 대상자는 실내와 실외 환경을 먼저 정하기 위하여 동전 던지기를 통해 실내 및 실외 환경의 순서를 정한 후, 4 가 지 임상 보행 평가의 측정을 위해 뽑기로 무작위 순서를 측정하였다. 본 연구의 실내 환경 보행은 피험자가 입원 해 있는 병원 건물의 복도에서 보행 시작점과 보행 끝 점 을 표기하고, 조용한 상황에서의 편안한 속도의 보행을 실시하였다 $[9,10]$. 본 연구의 실외 환경 보행은 담이나 벽이 있는 공간이 아닌 공간으로, 보행 시 다른 사람이나 물체가 보행의 방해를 받지 않는 곳(예, 야외 주차장 등) 에서 수행하였다. 실외 환경에서는 평지 경사도의 변화가 없고, 보행로에서는 어떠한 턱이나 장애물이 존재하지 않 는 곳으로서, 피험자가 입원해 있는 병원 건물 밖의 개방 된 공간에서 보행 시작점과 보행 끝 점을 표기하고, 조용 한 상황에서의 편안한 속도의 보행을 수행하였다[8-10]. 연구 대상자는 실내 환경과 실외 환경에서 임상 보행 평 가인 일어서서 걷기 시간(Timed up and go test, TUG), 10 미터 걷기 시간(10 m walking test, $10 \mathrm{WMT}), 8$ 자 모 양 경로 보행 검사(Figure 8 walk test, F8WT)와 기능적 보행 평가(Functional gait assessment, FGA)를 실시하였 다. $\mathrm{TUG}, 10 \mathrm{WMT}, \mathrm{F} 8 \mathrm{WT}$ 는 각각 3 번씩 측정하여 평균 값을 최종 결과 값으로 사용하였으며, $\mathrm{FGA}$ 는 한번만 측 정하여 결과 값으로 사용하였다. 각각의 임상 보행 측정 사이에서는 1 분간의 휴식 시간을 제공하였다.

\section{Clinical Gait Scales}

\section{기능적 이동성 범주(Functional Ambulatory Category, FAC)}

기능적 이동성 범주는 물리치료를 받는 환자들의 기능 적 이동 능력을 평가하는 목적으로 개발되었다. 임상가는 독립적으로 실외 보행이 가능한 경우부터 기능적으로 보 행이 안 되는 범주로 구분한다. 0점은 환자는 걸을 수 없 고 2 명 이상의 사람의 도움을 필요로 함, 1 점은 1 명의 도 움이 지속적으로 필요로 하여 체중과 균형을 도움을 받아 보행, 2 점은 1 명의 도움이 지속적 또는 간헐적으로 필요 로 하여 체중과 균형의 도움을 받아 보행, 3 점은 환자는 구두적인 감독 또는 물리적 접촉 없이 옆에서 도움을 받 아 보행, 4점은 환자는 평지에서 독립적으로 보행 할 수 있지만, 계단, 경사로 또는 바닥이 편평하지 않은 곳에서 는 도움을 받아 보행, 5점은 환자는 어떠한 곳에서도 독 립적으로 보행 가능함으로 구분한다[11]. FAC의 급성 뇌 졸중 환자에서 검사 재검사 신뢰도 Kappa $=0.95$ 이며[12], 본 연구에서는 10 미터 거리의 복도에서 편안한 속도로 
보행하도록 하여 관찰된 점수를 부여하였다[13].

\section{일어서서 걷기 시간(Timed Up and Go test)}

일어서서 걷기 시간은 노인의 넘어짐 위험과 걷기 능 력, 균형과 이동성을 평가하기 위하여 개발되었다. 피험자 는 등받이 의자에 앉은 상태에서 “시작(go)"과 동시에 의 자에서 일어서서 $3 \mathrm{~m}$ 를 편안한 속도로 걷고 돌아온 후, 다시 의자에 앉는 소요 시간을 측정한다[14]. 만성 뇌졸중 환자를 대상으로 7일 간격의 검사 재검사 신뢰도 $\mathrm{ICC}=$ 0.96으로 보고되고 있으며[15], 본 연구에서는 일어서서 걷기 시간을 3 번 측정하여 평균값을 최종 값으로 사용하 였다. 지역 사회 거주 노인에서 TUG가 13.5초 이상이면 넘어짐의 위험도가 증가하는 기준점(cut off score)이며 [16], 만성 뇌졸중 환자에서는 14 초 이상이 넘어짐의 위 험도가 증가하는 기준점이다[17].

\section{0미터 걷기 시간(10 m Walking Test)}

10 미터 걷기 시간은 짧은 거리의 보행 시 보행 속도를 평가하기 위하여 개발되었다. 10 미터의 정해진 거리를 걷 는 동안 소요되는 시간을 측정하는 것으로, 다양한 거리 를 적용하여 걷기 시간을 실시하지만, 일반적으로 10 미터 를 많이 사용한다. 편안한 속도로 걷도록 안내하고, 보조 도구를 사용하는 경우 보조도구 사용 여부에 대한 것을 기록하도록 되어 있다[18]. 만성 뇌졸중 환자를 대상으로 검사 재검사 신뢰도 $\mathrm{ICC}=0.95-0.99$ 로 보고되었다[19]. 본 연구에서는 10 미터 걷기 검사를 3 번 측정하여 평균값 을 최종 값으로 사용하였다. 뇌졸중 환자에서 10 미터 걷기 검사 결과 $0.4 \mathrm{~m} / \mathrm{s}$ 이하의 경우 가정 내에서만 이동이 가 능하고, $0.8 \mathrm{~m} / \mathrm{s}$ 이상일 경우 지역사회 이동이 가능하다 고 하였다[20]. Severinsen 등[21]은 뇌졸중 환자의 평균 10 미터 걷기 검사 속도는 $0.84 \pm 0.3 \mathrm{~m} / \mathrm{s}$ 으로 제시하였다.

\section{8자 모양 경로 보행 검새(Figure 8 Walk Test)}

8 자 모양 경로 보행 검사는 이동성 장애를 가진 노인 의 일상 생활의 보행 능력을 측정하기 위한 것이다. F8WT는 직선 보행과 곡선 보행을 포함하고 있으며, 8자 모양의 두 개의 콘 사이를 걷도록 한다. 두 개의 콘 사이 는 $150 \mathrm{~cm}$ 간격으로 위치하여, 보행하는 동안 소요되는 시 간과 소요되는 걸음 수를 평가한다[22]. 만성 뇌졸중 환자 의 검사 재검사 신뢰도는 $\mathrm{ICC}=0.94-0.99$ 로 보고되고 있다[23]. 본 연구에서는 3 번 측정하여 평균값을 최종 값 으로 사용하였다. Hess 등[22]은 지역 사회 거주 노인의 $\mathrm{F} 8 \mathrm{WT}$ 의 평균 소요 시간은 10.49 초, 평균 걸음 수는 17.51수로 보고하였다.

\section{기능적 보행 평가(Functional Gait Assessment)}

기능적 보행 평가는 보행 동안 다양한 움직임 과제를 수행하는 동안의 보행과 자세 안정성을 평가하기 위해 개 발되었다. $\mathrm{FGA}$ 는 8 개 항목의 동적 보행 지수(Dynamic Gait Index, DGI)의 천장 효과(ceiling effect)와 신뢰도를 개선하기 위하여 수정 보완된 평가 도구이다. 동적 보행 지수의 7 개 항목을 동일하게 사용하고, 3 개의 새로운 항 목을 추가하여 구성되었다. 10 개 항목은 평평한 지면에서 의 보행, 보행 속도 변경하기, 보행하면서 옆으로 머리를 돌리기, 보행하면서 상하로 머리를 움직이기, 보행하다가 한 발을 축으로 해서 돌기, 장애물 위를 지나 걷기, 좁은 기저면에서 걷기, 눈을 감고 걷기, 뒤로 걷기, 계단 오르 내리기로 구성되어 있다. 각각의 항목은 0 에서 3점을 부 여하게 되어 있으며, 0 점은 심각한 손상, 1 점은 중증도 손 상, 2점은 경미한 손상, 3점은 정상적 수행의 능력으로 점 수를 부여하며, 총점은 30 점이다[24]. 평가는 보조 도구를 사용하거나 사용하지 않을 수도 있으며, 평가 기록지에 보행 보조 도구 사용 여부를 기록하였다. FGA는 급성 뇌 졸중과 만성 뇌졸중 환자에서 검사 재검사 신뢰도 $\mathrm{ICC}=$ 0.95 로 보고되고 있다[25]. 본 연구에서는 $\mathrm{FGA}$ 를 1 번 측 정한 값을 이용하여 최종 값으로 사용하였다.

\section{Statistical Analysis}

본 연구 자료의 통계 분석은 윈도우용 통계프로그램 SPSS (version 26.0, SPSS Inc., U.S.A.)을 이용하였다. 연구 대상자의 일반적인 특성을 분석하기 위하여 기술 통 계를 사용하였다. 연구 대상자의 연령, 신장과 체중은 동 질성 검사를 하였으며, 유병 기간, 발병 원인, 마비 부위 와 $\mathrm{FAC}$ 점수의 결과 값 정규성 검정을 위하여 Kolmogorov-Smirnov를 실시하였다. 정규성 검사 결과에 따른 실내 환경과 실외 환경에서 보행 차이를 비교하기 위하여 짝 비교 $\mathrm{t}$ 대응 표본 검정(paired t-test)과 윌콕슨 순위 검정(Wilcoxon signed rank test)을 실시하였다. 모 든 자료의 통계학적 유의 수준은 0.05 로 하였다.

\section{Results}

\section{연구 대상자의 일반적 특성과 의학적 특성}

연구 대상자의 연령, 신장과 체중은 KolmogorovSmirnov를 실시하여 동질성을 확보하였으며, 일반적인 특성과 의학적 특성은 Table 1과 같았다. 
Table 1. General characteristics and medical characteristics

\begin{tabular}{ll} 
of subjects & \multicolumn{1}{c}{$(\mathrm{N}=57)$} \\
\hline & subjects \\
\hline Gender (male/female) & $40 / 17$ \\
Age (years) & $58.98 \pm 9.56^{\mathrm{a}}$ \\
Height (cm) & $166.05 \pm 8.67$ \\
Weight (kg) & $65.70 \pm 11.01$ \\
Onset (month) & $9.37 \pm 6.40$ \\
Etiology (infarction/hemorrhage) & $37 / 20$ \\
Affected side (right/left) & $34 / 23$ \\
FAC (2 / 3 / 4 / 5) & $15 / 24 / 15 / 3$
\end{tabular}

주. ${ }^{\mathrm{a}}$ mean \pm standard deviation,

$\mathrm{FAC}=$ Functional Ambulatory Category

\section{일어서서 걷기 시간}

일어서서 걷기 시간은 전체 대상자에서 실외 환경에서 통계적으로 유의하게 증가하였으며(Table 2$)(\mathrm{p}<0.05)$, 유 병 기간에 따른 실외 환경에서도 통계적으로 유의하게 증 가하였다 $(\mathrm{p}<0.05)$. 또한, 발병 원인과 마비 부위에 따른 실외 환경에서도 통계적으로 유의하게 증가하였다 $(\mathrm{p}<0.05)$. 그리고 $\mathrm{FAC} \mathrm{2,} \mathrm{3,} \mathrm{4점에서도} \mathrm{실외} \mathrm{환경에서} \mathrm{통계적으로}$ 유의하게 증가하였다 $(\mathrm{p}<0.05)$.

\section{0 미터 걷기 시간}

10 미터 걷기 시간은 전체 대상자에서 실외 환경에서 통계적으로 유의하게 증가하였으며(Table 3$)(\mathrm{p}<0.05)$, 유 병 기간에 따른 실외 환경에서도 통계적으로 유의하게 증 가하였다 $(\mathrm{p}<0.05)$. 또한, 발병 원인과 마비 부위에 따른 실외 환경에서도 통계적으로 유의하게 증가하였다 $(\mathrm{p}<0.05)$. 그리고 FAC 2, 3, 4점에서도 실외 환경에서 통계적으로 유의하게 증가하였다 $(\mathrm{p}<0.05)$.

\section{8자 모양 경로 보행 검사}

8자 모양 경로 보행의 소요 시간은 전체 대상자에서 실외 환경에서 통계적으로 유의하게 증가하였으며(Table $4)(p<0.05), 4$ 개월에서 6개월 이하, 그리고 7개월 이상에 서 실외 환경에서도 통계적으로 유의하게 증가하였다 $(\mathrm{p}$ $<0.05)$. 또한, 발병 원인과 마비 부위에 따른 실외 환경 에서도 통계적으로 유의하게 증가하였다 $(\mathrm{p}<0.05)$. 그리 고 FAC 2, 3, 4점에서도 실외 환경에서 통계적으로 유의 하게 증가하였다 $(\mathrm{p}<0.05)$.

8자 모양 경로 보행 시 걸음 수는 전체 대상자에서 실 외 환경에서 통계적으로 유의하게 증가하였으며(Table $4)(p<0.05), 4$ 개월에서 6 개월 이하, 그리고 7 개월 이상에 서 실외 환경에서도 통계적으로 유의하게 증가하였다 $(\mathrm{p}$ $<0.05)$. 또한, 발병 원인과 마비 부위에 따른 실외 환경 에서도 통계적으로 유의하게 증가하였다 $(\mathrm{p}<0.05)$. 그리 고 $\mathrm{FAC}$ 2점과 3점에서 실외 환경에서 통계적으로 유의 하게 증가하였다 $(\mathrm{p}<0.05)$.

Table 2. Timed up and go test according to indoor and outdoor environments

$(\mathrm{N}=57)$

\begin{tabular}{|c|c|c|c|c|c|c|c|c|c|}
\hline & & \multicolumn{3}{|c|}{ Indoor (sec) } & \multicolumn{3}{|c|}{ Outdoor (sec) } & \multirow{2}{*}{$\frac{t(z)}{-6.775}$} & \multirow{2}{*}{$\frac{p}{<0.001}$} \\
\hline \multicolumn{2}{|c|}{ Total $(\mathbf{N}=57)$} & 18.46 & \pm & $9.58^{\mathrm{a}}$ & 20.50 & \pm & 11.10 & & \\
\hline \multirow{3}{*}{$\begin{array}{l}\text { Onset } \\
\text { (month) }\end{array}$} & $0 \sim 3\left(\mathrm{n}_{1}=8\right)$ & 19.98 & \pm & 15.46 & 22.48 & \pm & 17.60 & 2.380 & 0.017 \\
\hline & $4 \sim 6\left(n_{2}=18\right)$ & 15.29 & \pm & 6.59 & 17.07 & \pm & 7.48 & -4.656 & $<0.001$ \\
\hline & $7 \sim\left(\mathrm{n}_{3}=31\right)$ & 19.91 & \pm & 9.07 & 21.98 & \pm & 10.75 & -4.481 & $<0.001$ \\
\hline \multirow[t]{2}{*}{ Etiology } & infarction $\left(\mathrm{n}_{1}=37\right)$ & 17.65 & \pm & 7.44 & 19.63 & \pm & 8.74 & -5.931 & $<0.001$ \\
\hline & hemorrhage $\left(\mathrm{n}_{2}=20\right)$ & 19.95 & \pm & 12.73 & 22.11 & \pm & 14.64 & 3.771 & $<0.001$ \\
\hline \multirow{2}{*}{$\begin{array}{l}\text { Affected } \\
\text { side }\end{array}$} & $\operatorname{right}\left(\mathrm{n}_{1}=34\right)$ & 18.96 & \pm & 9.39 & 21.08 & \pm & 11.11 & 4.454 & $<0.001$ \\
\hline & left $\left(\mathrm{n}_{2}=23\right)$ & 17.71 & \pm & 10.01 & 19.64 & \pm & 11.27 & 3.954 & $<0.001$ \\
\hline \multirow[t]{4}{*}{ FAC } & $2\left(\mathrm{n}_{1}=15\right)$ & 29.66 & \pm & 10.28 & 33.12 & \pm & 12.32 & 3.408 & 0.001 \\
\hline & $3\left(\mathrm{n}_{2}=24\right)$ & 16.24 & \pm & 5.33 & 18.21 & \pm & 6.19 & 3.686 & $<0.001$ \\
\hline & $4\left(n_{3}=15\right)$ & 12.45 & \pm & 4.31 & 13.47 & \pm & 5.02 & 2.726 & 0.006 \\
\hline & $5\left(\mathrm{n}_{4}=3\right)$ & 10.20 & \pm & 0.83 & 10.86 & \pm & 1.11 & 1.604 & 0.109 \\
\hline
\end{tabular}

주. ${ }^{\mathrm{a}}$ mean \pm standard deviation, $\mathrm{FAC}=$ Functional Ambulatory Category. 
Table 3. 10-meter walk test according to indoor and outdoor environments

$(\mathrm{N}=57)$

\begin{tabular}{lllllllll}
\hline & \multicolumn{2}{l}{ Indoor $(\mathbf{s e c})$} & \multicolumn{2}{c}{ Outdoor $(\mathbf{s e c})$} & \multicolumn{1}{c}{$\mathbf{t}(\mathbf{z})$} & \multicolumn{1}{c}{$\boldsymbol{p}$} \\
\hline Total $(\mathbf{N}=\mathbf{5 7})$ & $\mathbf{1 7 . 5 7}$ & \pm & $\mathbf{9 . 0 1}$ & $\mathbf{1 9 . 3 2}$ & $\pm \mathbf{1 0 . 0 5}$ & $\mathbf{6 . 9 3 2}$ & $<\mathbf{0 . 0 0 1}$ \\
\hline Onset & $0 \sim 3\left(\mathrm{n}_{1}=8\right)$ & 19.43 & \pm 13.55 & 20.66 & \pm 14.53 & 2.100 & 0.036 \\
(month) & $4 \sim 6\left(\mathrm{n}_{2}=18\right)$ & 14.66 & \pm 6.30 & 16.08 & \pm 6.74 & 3.245 & 0.001 \\
& $7 \sim\left(\mathrm{n}_{3}=31\right)$ & 18.79 & \pm 8.87 & 20.86 & \pm 10.22 & -5.669 & $<0.001$ \\
\hline Etiology & infarction $\left(\mathrm{n}_{1}=37\right)$ & 17.24 & \pm 7.56 & 18.72 & \pm 8.34 & -5.688 & $<0.001$ \\
& hemorrhage $\left(\mathrm{n}_{2}=20\right)$ & 18.20 & \pm 11.41 & 20.44 & \pm 12.81 & 3.771 & $<0.001$ \\
\hline Affected & right $\left(\mathrm{n}_{1}=34\right)$ & 18.24 & \pm 9.33 & 20.04 & \pm 10.41 & 4.590 & $<0.001$ \\
side & left $\left(\mathrm{n}_{2}=23\right)$ & 16.59 & \pm 8.62 & 18.25 & \pm 9.62 & 3.893 & $<0.001$ \\
\hline FAC & $2\left(\mathrm{n}_{1}=15\right)$ & 28.71 & \pm 9.06 & 31.58 & \pm 10.27 & 3.351 & 0.001 \\
& $3\left(\mathrm{n}_{2}=24\right)$ & 15.10 & \pm 4.39 & 17.06 & \pm 4.63 & 4.286 & $<0.001$ \\
& $4\left(\mathrm{n}_{3}=15\right)$ & 12.04 & \pm 4.46 & 12.71 & \pm 4.98 & 2.131 & 0.033
\end{tabular}

주. ${ }^{\mathrm{a}}$ mean \pm standard deviation, $\mathrm{FAC}=$ Functional Ambulatory Category.

Table 4. Figure-eight walk test according to indoor and outdoor environments

$(\mathrm{N}=57)$

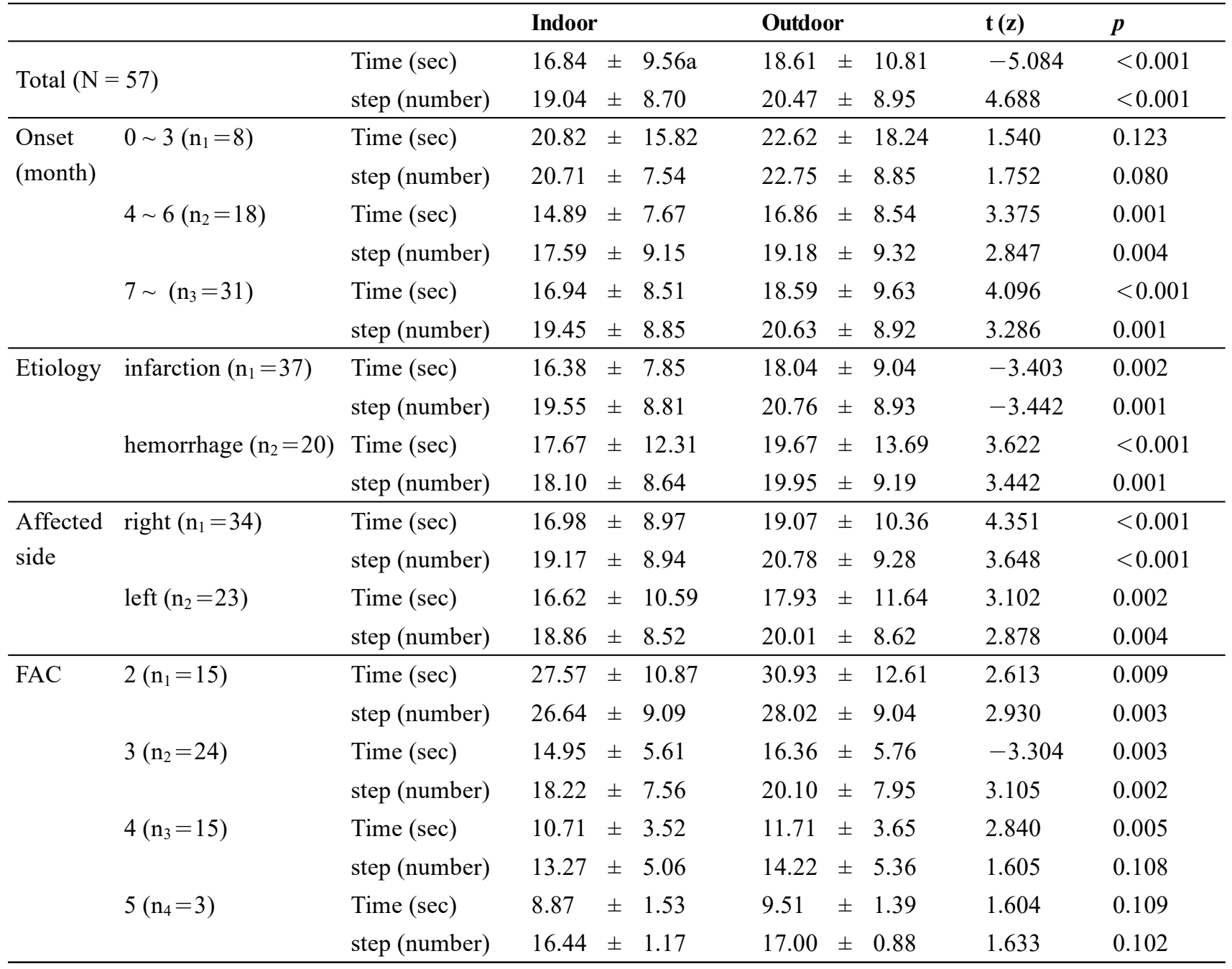

주. ${ }^{\mathrm{a}}$ mean \pm standard deviation, $\mathrm{FAC}=$ Functional Ambulatory Category. 


\section{기능적 보행 평가 점수}

$\mathrm{FGA}$ 전체 점수는 전체 대상자에서 실외 환경에서 통 계적으로 유의하게 낮게 나타났으며(Table 5$)(\mathrm{p}<0.05), 4$ 개월에서 6 개월 이하, 그리고 7 개월 이상에서 실외 환경 에서도 통계적으로 유의하게 낮게 나타났다 $(\mathrm{p}<0.05)$. 또 한, 발병 원인과 마비 부위에 따른 실외 환경에서도 통계 적으로 유의하게 낮게 나타났으며(p<0.05), FAC 2, 3, 4 점에서도 실외 환경에서 통계적으로 유의하게 낮게 나타 났다 $(\mathrm{p}<0.05)$.

\section{계단 오르내리기 항목 및 소요 시간}

FGA 10 번 항목의 계단 오르내리기는 실제 계단 오르 내리기 항목을 수행하지 못한 대상자를 제외하고 분석한 전체 대상자 중 45 명에서 통계적으로 유의한 차이가 나타 나지 않았다(Table 6).

FGA 10번 항목의 계단 오르내리기는 실제 계단 오르 내리기 항목을 수행하지 못한 대상자를 제외하고 분석한 전체 대상자 45 명에서 소요 시간은 전체 대상자의 실외 환경에서 통계적으로 유의하게 증가하였다(Table 6)(p $<0.05)$. 유병 기간, 발병 원인과 마비 부위에 따른 실외 환경에서의 소요 시간은 통계적으로 유의하게 증가하였다 $(\mathrm{p}<0.05)$. 그리고, $\mathrm{FAC}$ 2과 3점에서 계단 오르내리기 소요 시간은 실외 환경에서 통계적으로 유의하게 증가하 였다 $(\mathrm{p}<0.05)$.

\section{Discussion}

본 연구는 뇌졸중 환자를 대상으로 실내 환경과 실외 환경에서 보행의 능력의 차이를 알아보고자 하였다. 동일 한 연구 대상자에게 TUG, 10WMT, F8WT와 FGA를 실 내 환경과 실외 환경에서 비교하였다. 연구 결과, 유병 기 간, 발병 원인, 마비 부위에 상관없이 실외 환경에서 실내 환경보다 TUG, 10WMT와 F8WT에서 통계적으로 유의 하게 증가하였다 $(\mathrm{p}<0.05)$. 하지만, $\mathrm{FAC}$ 에 따른 2점, 3점, 4점에서는 실외 환경에서 실내 환경보다 $\mathrm{FGA}$ 점수가 통 계적으로 유의하게 감소하였지만, 5 점에서는 $\mathrm{FGA}$ 는 통계 적으로 유의한 차이가 나타나지 않았다. 또한, $\mathrm{FGA}$ 의 10 번 항목인 계단 오르내리기는 실내 환경과 실외 환경에서 통계적으로 유의한 차이가 나타나지 않았지만, 실외 환경 에서 계단 오르내리기 소요 시간은 FAC 2점과 3점에서 통계적으로 유의하게 증가하였으며, 4점과 5점에서는 통 계적으로 유의한 차이가 나타나지 않았다.

본 연구에서 $\mathrm{TUG}$ 는 실내 환경에서 $18.46 \pm 9.58$ 초, 실 외 환경에서 $20.50 \pm 11.10$ 초로 통계적으로 유의하게 증가 하였다. Shumway-Cook 등[16]은 지역 사회 거주 노인의 $\mathrm{TUG}$ 는 13.5 초 이상이며 넘어짐의 위험도가 증가하는 기 준점이라고 하였으며, Andersson 등[17]은 만성 뇌졸중 환자의 $\mathrm{TUG}$ 는 14 초 이상일 경우 넘어짐의 위험도가 증 가한다고 하였다. 본 연구에서 $\mathrm{TUG}$ 는 일반적인 특성에 상관없이 대부분 넘어짐의 위험도가 증가하는 14 초 이상

Table 5. Functional gait assessment according to indoor and outdoor environments

$(\mathrm{N}=57)$

\begin{tabular}{|c|c|c|c|c|c|c|c|c|c|}
\hline & & \multicolumn{3}{|c|}{ Indoor } & \multicolumn{3}{|c|}{ Outdoor } & \multirow{2}{*}{$\begin{array}{l}t(z) \\
6.524\end{array}$} & \multirow{2}{*}{$\begin{array}{l}p \\
<0.001\end{array}$} \\
\hline \multicolumn{2}{|c|}{ Total $(N=57)$} & 18.21 & \pm & $7.33^{\mathrm{a}}$ & 16.40 & \pm & 7.10 & & \\
\hline \multirow{3}{*}{$\begin{array}{l}\text { Onset } \\
\text { (month) }\end{array}$} & $0 \sim 3\left(\mathrm{n}_{1}=8\right)$ & 18.10 & \pm & 9.17 & 15.30 & \pm & 8.05 & -1.841 & 0.066 \\
\hline & $4 \sim 6\left(\mathrm{n}_{2}=18\right)$ & 20.20 & \pm & 7.07 & 19.10 & \pm & 6.81 & -2.980 & 0.003 \\
\hline & $7 \sim\left(\mathrm{n}_{3}=31\right)$ & 17.10 & \pm & 6.96 & 15.10 & \pm & 6.81 & -3.859 & $<0.001$ \\
\hline \multirow[t]{2}{*}{ Etiology } & infarction $\left(\mathrm{n}_{1}=37\right)$ & 17.70 & \pm & 7.52 & 16.20 & \pm & 7.11 & -3.845 & $<0.001$ \\
\hline & hemorrhage $\left(\mathrm{n}_{2}=20\right)$ & 19.20 & \pm & 7.04 & 16.90 & \pm & 7.25 & -3.431 & 0.001 \\
\hline \multirow{2}{*}{$\begin{array}{l}\text { Affected } \\
\text { side }\end{array}$} & Right $\left(\mathrm{n}_{1}=34\right)$ & 17.90 & \pm & 7.00 & 16.20 & \pm & 6.87 & -3.734 & $<0.001$ \\
\hline & Left $\left(\mathrm{n}_{2}=23\right)$ & 18.70 & \pm & 7.91 & 16.70 & \pm & 7.57 & -3.545 & $<0.001$ \\
\hline \multirow[t]{4}{*}{ FAC } & $2\left(\mathrm{n}_{1}=15\right)$ & 10.70 & \pm & 4.86 & 9.50 & \pm & 4.88 & -2.699 & 0.007 \\
\hline & $3\left(\mathrm{n}_{2}=24\right)$ & 18.80 & \pm & 6.90 & 16.50 & \pm & 6.48 & -3.424 & 0.001 \\
\hline & $4\left(n_{3}=15\right)$ & 23.50 & \pm & 3.78 & 22.10 & \pm & 4.01 & -2.443 & 0.015 \\
\hline & $5\left(\mathrm{n}_{4}=3\right)$ & 24.00 & \pm & 1.73 & 22.00 & \pm & 1.00 & -1.342 & 0.180 \\
\hline
\end{tabular}

주. ${ }^{\mathrm{a}}$ mean \pm standard deviation, $\mathrm{FAC}=$ Functional Ambulatory Category. 
Table 6. Timed stairs up and down according to indoor and outdoor environments

$(\mathrm{N}=57)$

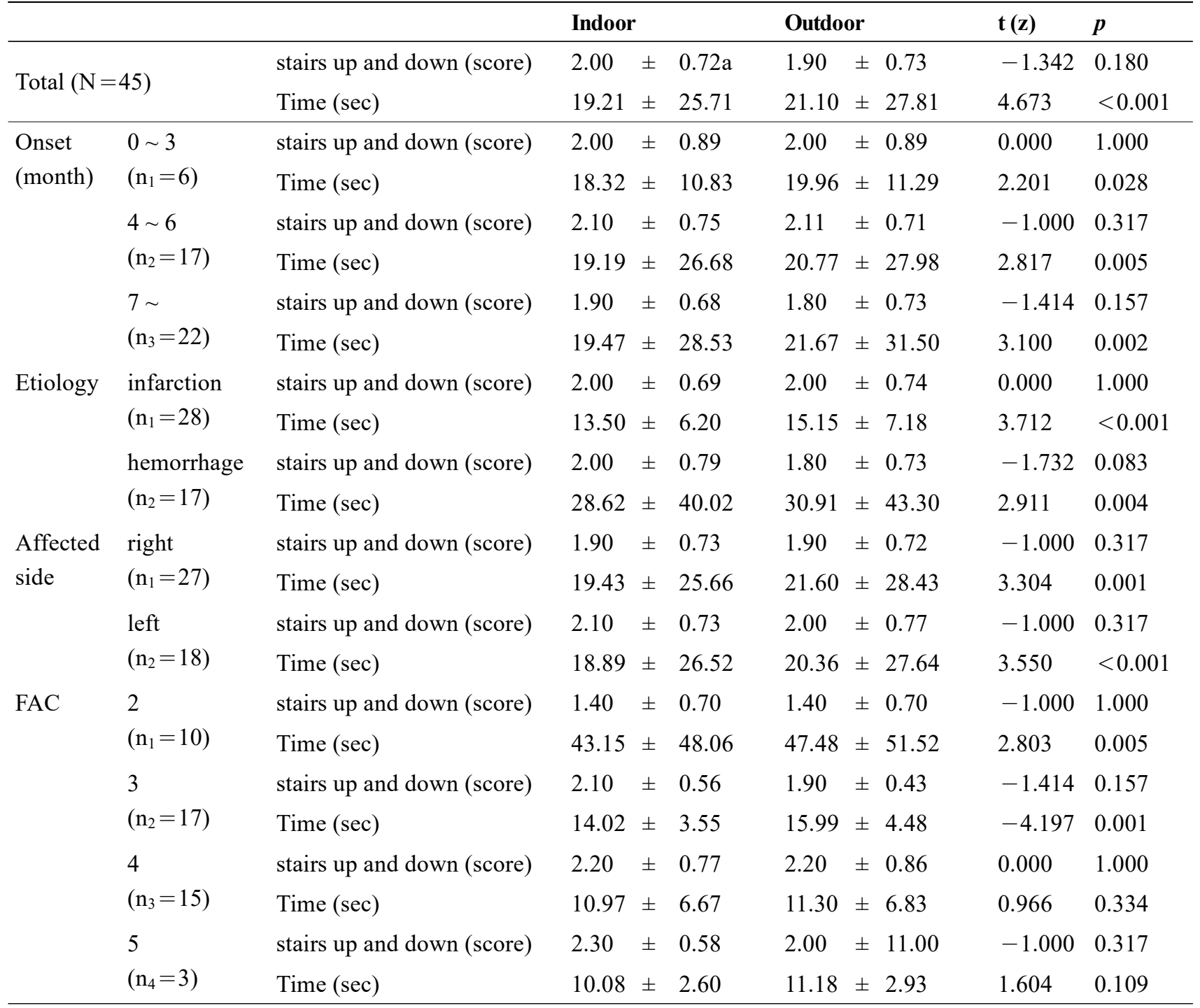

주. ${ }^{\mathrm{a}}$ mean \pm standard deviation, $\mathrm{FAC}=$ Functional Ambulatory Category.

으로 측정되었으나, FAC 4점과 5점에서는 14초 이하의 값을 보여주었다. $\mathrm{FAC}$ 4점은 환자가 평지에서 독립적으 로 보행을 할 수 있지만, 계단, 경사로 또는 바닥이 편평 하지 않은 곳에서 도움을 받아 보행, 5점은 어떠한 곳에 서도 독립적으로 보행을 할 수 있는 능력으로 구분한다. 본 연구에서 전체 뇌졸중 환자의 실내 환경보다 실외 환 경에서 $\mathrm{TUG}$ 는 평균 2.04초가 증가하였으며, 특히 $\mathrm{FAC}$ 2점에서는 평균 3.46 초가 실외 환경에서 증가하였다. $\mathrm{TUG}$ 는 뇌졸중 환자의 낙상 위험을 예측하는데 있어 매 우 유용한 도구로서[1], 본 연구에서 FAC 4점의 경우 실 외 환경에서 실내보다 평균 1.02 초가 증가하였지만, 통계 적으로 유의한 증가를 보여준 것은 실외 환경에서 보다 많은 인지 능력과 환경에 대한 상호 작용이 보행 시 요구
되는 것으로 생각된다. 하지만, FAC 5점의 경우 통계적 으로 유의한 차이를 보이지 않은 것은 5 점에 해당하는 연 구 대상자가 3 명이고, 5 점에 해당하는 능력 자체가 어떠 한 환경에서도 독립 보행이 가능한 경우이기 때문에 통계 적으로 유의한 차이가 나타나지 않았다고 생각된다.

본 연구에서 $10 \mathrm{MWT}$ 는 실내 환경에서 17.57 \pm 9.01 초, 실외 환경에서 $19.32 \pm 10.05$ 초로 통계적으로 유의하게 증 가하였다. Schmid 등[20]은 뇌졸중 환자의 $10 \mathrm{MWT}$ 결과 $0.4 \mathrm{~m} / \mathrm{s}$ 이하의 경우 가정 내 이동 수준이며, $0.8 \mathrm{~m} / \mathrm{s}$ 이 상의 경우만 지역 사회 이동 가능한 수준이라고 하였다. 본 연구에서 실내 환경에서 소요된 시간을 보행 속도로 변환하면 $0.60 \mathrm{~m} / \mathrm{s}$, 실외 환경에서 $0.52 \mathrm{~m} / \mathrm{s}$ 로 나타났다. $10 \mathrm{MWT}$ 는 임상에서 속도를 측정하는데 빈번하게 사용하 
는 평가 도구로서, Perera 등[26]은 최소 임상적 중요 차 이값(minimally clinically important difference, MCID) 의 최소값을 $0.06 \mathrm{~m} / \mathrm{s}$, 실질적 의미값 $0.14 \mathrm{~m} / \mathrm{s}$ 로 보고하 였다. 본 연구에서도 $10 \mathrm{MWT}$ 는 실외 환경에서 평균 0.08 $\mathrm{m} / \mathrm{s}$ 감소하여 임상적 중요 차이값을 보여준 것은 TUG와 같이 실외 환경에서 보행 능력이 감소되는 것을 반영하는 결과라고 할 수 있다. 하지만, FAC 5점에서는 실내 환경 에서 $1.07 \mathrm{~m} / \mathrm{s}$, 실외 환경에서 $1.09 \mathrm{~m} / \mathrm{s}$ 로서 통계적으로 유의한 차이가 나타나지 않았다. 이는 선행 연구에서 지 역사회 이동 가능하다고 제시한 값으로 본 연구에서도 실 외 환경에서는 의미 있는 차이가 나타나지 않았다.

본 연구의 $\mathrm{F} 8 \mathrm{WT}$ 의 소요 시간은 실내 환경에서 $16.84 \pm 9.56$ 초, 실외 환경에서 $18.61 \pm 10.81$ 초, 걸음 수는 실내 환경에서 $19.04 \pm 9.56$ 수, 실외 환경에서 $20.47 \pm 8.95$ 수로 통계적으로 유의하게 증가하였다. Hess 등[22]은 지 역 사회 거주 노인의 $\mathrm{F} 8 \mathrm{WT}$ 의 평균 소요 시간은 10.49 초, 평균 걸음 수는 17.51 수로 제시하였다. 본 연구에서 뇌졸 중 환자는 Hess 등[22]이 제시한 지역 사회 거주 노인의 평균 소요 시간과 평균 걸음 수 보다 증가하게 나타났다. 본 연구에서 $\mathrm{F} 8 \mathrm{WT}$ 를 위해서는 두 개의 콘 사이를 직선 과 곡선으로 보행하는 과제를 수행한다. TUG와 $10 \mathrm{MWT}$ 는 보행에 소요되는 시간을 측정하지만, F8WT는 걷는데 소요되는 시간과 걸음 수를 측정하며, TUG와 $10 \mathrm{MWT}$ 보다 많은 곡선이 포함되어, 비교적 어려울 수 있는 보행 을 수행하게 되는 특성을 가지고 있다. 따라서, 실외 환경 에서 TUG와 $10 \mathrm{MWT}$ 에서 증가한 소요 시간이 F8WT의 소요 시간에서도 유사하게 증가하였으며, 걸음 수 또한 증가하는 양상을 보였다. 또한, $\mathrm{FAC} 2$ 점과 3 점에서는 통 계적으로 유의하게 증가하였지만, FAC 4점에서는 소요 시간은 통계적으로 유의하게 증가하였지만, 평균 걸음 수 는 증가하였지만, 통계적으로 유의한 값이 나타나지 않았 다. Ho 등[6]은 과제 지향적인 인지 부하량이 증가하게 되면 보행 변수 중 걸음 시간이 증가하고, 특히 실외 환경 에서 걸음 시간이 증가한다고 하였다. 본 연구에서도 두 개의 콘 사이를 8 자 모양으로 걷는 검사는 기존 보행 검 사와 다르게 곡선 구간을 포함하고 있고, 보행 동안 균형 등 다양한 능력이 요구되는 만큼 소요 시간과 걸음 수가 증가한 것으로 생각된다. 특히, 실외 환경에서는 이러한 복잡할 수 있는 과제가 보행 검사로 인하여 소요 시간과 걸음 수가 증가한 것으로 생각된다. 하지만, $\mathrm{FAC} 5$ 점의 평균 소요 시간은 Hess 등[22]이 제시한 지역 사회 거주 노인 보다 적은 값을 보여주었으며, 이러한 값은 실외 환 경에서 소요 시간과 걸음 수의 차이가 나타나지 않은 것 으로 생각된다.

본 연구에서 $\mathrm{FGA}$ 점수는 실내 환경에서 $18.21 \pm 7.33$ 점, 실외 환경에서 $16.40 \pm 7.10$ 점으로 통계적으로 유의하
게 감소하였다. Beninato 등[27]은 지역 사회 거주 노인 의 FGA 점수가 22점 이하일 경우 낙상 위험의 기준점으 로 제시하였으며, Walker 등[24]은 나이가 증가함에 따라 전반적으로 $\mathrm{FGA}$ 점수가 감소하며, 나이 증가에 따른 변 화량도 증가한다고 하였다. 특히 50 대의 평균 FGA 점수 를 28.4점, 60 대의 $\mathrm{FGA}$ 평균 점수는 27.1점, 그리고 70 대의 $\mathrm{FGA}$ 평균 점수는 24.9점, 80 대의 $\mathrm{FGA}$ 평균 점수 는 20.8 점으로 제시하였다. $\mathrm{FGA}$ 는 보행의 시간적 변수를 측정하는 것이 아니며, 보행 중 보행 속도 변경, 머리 돌 리기, 한 발을 축으로 돌기, 장애물 위로 걷기, 좁은 기저 면 걷기와 같은 보행 시 과제 수행 능력을 질적인 변수를 평가하는 방식으로[24], 본 연구에 참여한 뇌졸중 환자의 평균 FGA 점수는 선행 연구에서 제시한 점수 보다 전반 적으로 낮게 나타났다. 특히, 본 연구에 참여한 뇌졸중 환 자의 평균 연령 $58.98 \pm 9.56$ 세를 고려한다면, 정상인과의 차이는 더욱 크다고 볼 수 있다. 하지만, Lin 등[25]은 뇌 졸중 환자의 재활 1 주 후 중위 값은 13 점, 2 개월에서 12 점으로 제시하여, 본 연구에서 참여한 뇌졸중 환자의 $\mathrm{FGA}$ 가 더 높게 나타났다. 또한 뇌졸중 환자에서 $\mathrm{FGA}$ 의 $\mathrm{MDC}$ 값은 4.2점, $14.1 \%$ 의 값으로 제시되고 있으며, 본 연구에서는 실내 환경과 실외 환경에서 값의 차이와도 비 교할 수 있었다. 이러한 것은 보행 시 필요로 하는 많은 신체 구조와 기능, 그리고 균형 등의 능력이 뇌졸중 환자 가 가지고 있는 전형적인 문제점으로 인하여 보행의 어려 움을 포함하고 있기 때문이라 생각된다.

FGA 10번 항목의 계단 오르내리기 시 소요 시간을 측정하였다. 계단 오르내리기 시 소요 시간은 실내 환경 에서 $15.43 \pm 24.03$ 초, 실외 환경에서 $16.66 \pm 26.13$ 초로 통 계적으로 유의하게 증가하였다. 하지만, 이러한 값은 실 제 계단 오르내리기를 수행할 수 없는 12 명을 포함하고, 이 대상자들의 소요 시간을 0 초로 계산한 값으로 실제 과 제 수행을 하지 못한 대상자 12 명을 제외한 45 명의 실제 소요 시간은 실내 환경에서 $19.21 \pm 25.71$ 초, 실외 환경에 서 21.10 \pm 27.81 초로 통계적으로 유의하게 증가하였으며, 평균 값의 차이도 더 크게 증가하였다. 계단 오르내리기 는 치료실에서 일반적으로 사용하는 계단을 이용하여 4 개의 계단을 본 측정에 사용하였다. Hirota 등[28]과 Sun 등[29]은 4개의 계단을 이용하여 노인들을 대상으로 계단 오르내리기 검사를 실시하였으며, Hirota 등[28]은 남성 노인에서 평균 5.28초, 여성 노인에서 5.88초로 제시하였 다. 본 연구에서도 Hirota 등[28]이 사용한 계단 수와 동 일하게 사용하였지만, Hirota 등[28]이 계단의 높이는 10 $\mathrm{cm}$ 를 사용하였다. 본 연구에서 사용한 치료실의 계단 높 이는 $15.5 \mathrm{~cm}$, 그리고 실외 환경에서 사용한 계단의 높 이는 $17.5 \mathrm{~cm}$ 이었다. 따라서, 본 연구에서 4 개 계단의 오 르내리기 소요 시간이 Hirota 등[28]이 제시한 값보다 오 
래 걸리게 된 것은 계단 높이로 인한 계단 보행 시 운동 역학적 변수의 변화와 뇌졸중 환자가 가지고 있는 신체 구조와 기능의 문제점이 더 많이 반영되어 나타났다고 생 각된다. 또한, 본 연구에서 $\mathrm{FAC}$ 2점과 3점에서는 소요 시간의 차이가 있었지만, 4점과 5점에서는 소요 시간의 차이는 나타나지 않았다. 이는 계단 오르내리기 과제 수 행을 하는 동안 계단의 레일을 잡는 것을 허용하고 환자 들이 일정 수준의 보행이 가능한 FAC 4점과 5점에서는 레일을 잡고 오르내리기를 하였기 때문이라고 생각된다. 그러나, FAC 2점과 3점은 보행 능력이 부족하기 때문에 레일을 잡아도 소요 시간이 더 필요하였을 것이라고 생각 된다.

본 연구에서 보행 능력을 $\mathrm{FAC}$ 로 분류하여 사용하였는 데, $\mathrm{FAC} 5$ 점에서는 실내 환경과 실외 환경에서의 보행 능력의 차이가 나타나지 않았다. 이는 FAC 5점의 경우, 환자는 어떠한 곳에서도 독립적으로 보행 가능함으로 구 분되며, 본 연구에서도 실내 환경뿐만 아니라 실외 환경 에서도 독립적이며 안정적으로 보행을 하여 통계적으로 유의한 차이를 보여주지 않았던 것으로 생각된다. 또한, 본 연구에서는 FAC 5 점의 환자는 3 명만 참가하여, 대상 자 수가 적은 부분도 있을 것이라 생각된다. 하지만, 본 연구에서 전체 대상자로 실내 환경과 실외 환경을 비교하 였을 경우, 실내 환경보다 실외 환경에서 보행 능력이 감 소함을 보여주었으며, $\mathrm{FAC}$ 점수별로 비교 분석한 결과 $\mathrm{FAC}$ 점수가 높아질수록 실외 환경의 감소하는 항목은 차 이가 줄어들거나 통계적으로 유의하게 나타나지 않았다.

본 연구에서는 임상 현장에서 신뢰도와 타당도가 입증 된 임상 보행 평가를 이용하여 실내 환경과 실외 환경의 보행 능력을 비교하고자 하였다. 하지만, 본 연구를 수행 함에 있어서 임상 보행 평가의 신뢰도를 가진 평가 도구 를 사용하였음에도 불구하고 다기관 평가로서 각 환자에 게 제시되는 환경적인 부분의 차이가 있었으며 FAC 점수 에 따른 다양한 보행 능력 수준에 따른 환자 수가 제한적 이었다. 특히, $\mathrm{FAC}$ 5점의 해당하는 대상자가 3 명으로 $\mathrm{FAC} 5$ 점에 대한 실내 환경과 실외 환경 보행 능력의 차 이를 일반화하기에는 제한적이다. 또한, FGA 10 번 항목 의 계단 오르내리기 항목의 경우, 실제 치료실에서 사용 하는 계단의 높이와 병원 또는 상가 건물에서 사용하는 계단 높이의 차이로 인한 계단 보행 시 운동 역학적 변화 성은 측정 및 평가할 수 없었다. 그리고 병원 또는 상가 건물에서의 계단 보행은 TUG, $10 \mathrm{MWT}$ 와 F8WT에서 실 시한 개방된 공간에서 실시할 수 없었기 때문에 일반화하 는데 제한점이 발생할 수 있다. 향후 연구에서는 실외 환 경 보행 시 좀 더 정밀한 시공간적 변수를 측정할 수 있 는 측정 장비와 다양한 보행 능력의 대상자로 비교하는 연구가 필요할 것이라 생각된다.

\section{Conclusions}

본 연구는 뇌졸중 환자를 대상으로 실내 환경과 실외 환경에서의 보행 능력을 비교하고자 하였다. 연구 대상자 는 $\mathrm{FAC}$ 를 평가하고 실내 환경과 실외 환경에서 $\mathrm{TUG}$, $10 \mathrm{MWT}, \mathrm{F} 8 \mathrm{WT}$ 와 FGA를 실시하였다. 연구 결과, 일반 적 특성에 따른 모든 임상적 보행 평가 항목에서 실외 환 경의 보행 능력이 실내 환경의 보행 능력보다 감소함을 나타냈다. 하지만, FAC에 따른 뇌졸중 환자의 보행 능력 의 수준은 낮은 수준에서는 실외 환경에서 보행 능력이 감소하였지만 높은 점에서는 실내 환경과 실외 환경에서 보행 능력의 차이가 나타나지 않았다. 따라서, 뇌졸중 환 자의 퇴원 후 보행 능력과 사회 참여를 위한 준비 과정에 서 실외 보행 능력에 대한 측정과 개방된 공간에서의 보 행 속도 변경하기나 실외 환경에서의 장애물 넘기 같은 실외 보행 훈련을 물리치료 프로그램에 고려한다면 효과 적인 퇴원 후 재활 복귀에 도움이 되리라 사료된다.

\section{Conflict of Interest}

The authors declare that they have no conflict of interests.

\section{References}

1. An JA, Lee BH. Reliability of joint angle during sit-to-stand movements in persons with stroke using portable gait analysis system based wearable sensors. Phys Ther Rehabil Sci. 2019;8(3):146-151.

2. Ahn SN, Hwang S. An investigation of factors influencing the participation of stroke survivors in social and leisure activities. Phys Ther Rehabil Sci. 2018;7(2):67-71.

3. Jacobs JM, Cohen A, Hammerman-Rozenberg R, Azoulay D, Maaravi Y, Stessman J. Going outdoors daily predicts long-term functional and health benefits among ambulatory older people. J Aging Health. 2008;20(3):259-272.

4. de Rooij IJM, van de Port IGL, Visser-Meily JMA, Meijer JWG. Virtual reality gait training versus non-virtual reality gait training for improving participation in subacute stroke survivors: study protocol of the ViRTAS randomized controlled trial. Trials. 2019;20(1):89.

5. Kuntapun J, Silsupadol P, Kamnardsiri T, Lugade V. 
Smartphone monitoring of gait and balance during irregular surface walking and obstacle crossing. Front Sport Act Living. 2020;2:560-577.

6. Ho S, Mohtadi A, Daud K, Leonards U, Handy TC. Using smartphone accelerometry to assess the relationship between cognitive load and gait dynamics during outdoor walking. Sci Rep. 2019;9(1):3119.

7. Praschiv-lonescu A, Newman CJ, Carcreff L, Gerber CN, Armand S, Aminian K. Locomotion and cadence detection using a single trunk-fixed accelerometer: validity for children with cerebral palsy in daily life-like conditions. J Neuroeng Rehabil. 2019;16(1):24.

8. Storm FA, Buckley CJ, Mazzà C. Gait event detection iin laboratory and real life settings: accuracy of ankle and waist sensor based methods. Gait Posture. 2016;50:42-46.

9. Tamburini P, Storm F, Buckley C, Bisi MC, Stagni R, Mazzà C. Moving from laboratory to real life conditions: influence on the assessment of variability and stability of gait. Gait Posture. 2018;59: 248-252.

10. Toda H, Maruyama T, Tada M. Indoor vs. outdoor walking: does it make any difference in joint angle depending on road surface? Front Sports Act Living. 2020;2:119.

11. Holden MK, Gill KM, Magliozzi MR. Gait assessment for neurologically impaired patients. Standards for outcome assessment. Phys Ther. 1986;66(10): 1530-1539.

12. Mehrholz J, Wagner K, Rutte K, Meissner D, Pohl M. Predictive validity and responsiveness of the funtional ambulation category in hemiparetic patients after stroke. Arch Phys Med Rehabil. 2007;88(10):1314-1319.

13. Holden MK, Gill KM, Magliozzi MR, Nathan J, Piehl-Baker L. Clinical gait assessment in the neurologically impaired. Reliability and meaningfulness. Phys Ther. 1984;64(1):35-40.

14. Podsiadlo D, Richardson S. The timed "Up \& Go": a test of basic functional mobility for frail elderly persons. J Am Geriatr Soc. 1991;39(2):142-148.

15. Flansbjer UB, Holmbäck AM, Downham D, Patten C, Lexell J. Reliability of gait performance tests in men and women with hemiparesis after stroke. J Rehabil Med. 2005;37(2):75-82.
16. Shumway-Cook A, Brauer S, Woollacott M. Predicting the probability fro falls in community-dwelling older adults using the Timed Up \& Go test. Phys Ther. 2000;80(9):896-903.

17. Andersson AG, Kamwendo K, Seiger A, Appelros P. How to identify potential fallers in a stroke unit: validity indexes of 4 test methods. J Rehabil Med. 2006;38(3):186-191.

18. Watson MJ. Refining the ten-metre walking test for use with neurologically impaired people. Physiother 2002;88(7):386-397.

19. Collen FM, Wade DT, Bradshaw CM. Mobility after stroke: reliability of measures of impairment and disability. Int Disabil Stud. 1990;12(1):6-9.

20. Schmid A, Duncan PW, Studenski S, Lai SM, Richards $\mathrm{L}$, Subashan $\mathrm{P}$, et al. Improvements in speed-based gait classifications are meaningful. Stroke. 2007; 38(7):2096-2100.

21. Severinsen K, Jakobsen JK, Overgaard K, Andersen H. Normalized muscle strength, aerobic capacity, and walking performance in chronic stroke: a population-based study on the potential for endurance and resistance training. Arch Phys Med Rehabil. 2011;92(10):1663-1668.

22. Hess RJ, Brach JS, Piva SR, VanSwearingen JM. Walking skill can be assessed in older adults: validity of the Figure-of- 8 Walk test. Phys Ther. 2010;90(1):89-99.

23. Wong SST, Yam MS, Ng SSM. The Figure-of-Eight Walk test: reliability and associations with stroke-specific impairments. Disabil Rehabil. 2013;35(22): 1896-1902.

24. Walker ML, Austin AG, Banke GM, Foxx SR, Gaetano L, Gardner LA, et al. Reference group data for the functional gait assessment. Phys Ther. 2007;87(11):1468-1477.

25. Lin JH, Hsu MJ, Hsu HW, Wu HC, Hsieh CL. Psychometric comparisons of 3 functional ambulation measures for patients with stroke. Stroke. 2010;41(9):2021-2025.

26. Perera S, Mody SH, Woodman RC, Studenski SA. Meaningful change and responsiveness in common physical performance measures in older adults. J Am Geriatr So. 2006;54(5):743-749.

27. Beninato M, Fernandes A, Plummer LS. Minimal clinically important difference of the Funtional Gait 
Assessment in older adults. Phys Ther. 2014;94(11): 1594-1603.

28. Hirota C, Wantanabe M, Sun W, Tanimoto Y, Kono $\mathrm{R}$, Takasaki $\mathrm{K}$, et al. Association between the trail making test and physical performance in elderly Japanese. Geriati Gerontol Int. 2010;10(1):40-47.

29. Sun W, Watanabe M, Hirota C, Tanimoto Y, Kono $\mathrm{R}$, Takasaki K. Obstacle-negotiating gait and related physical measurement indicators for the community-dwelling elderly in Japan. Arch Gerontol Geriatr. 2010;50(3):e41-e45. 